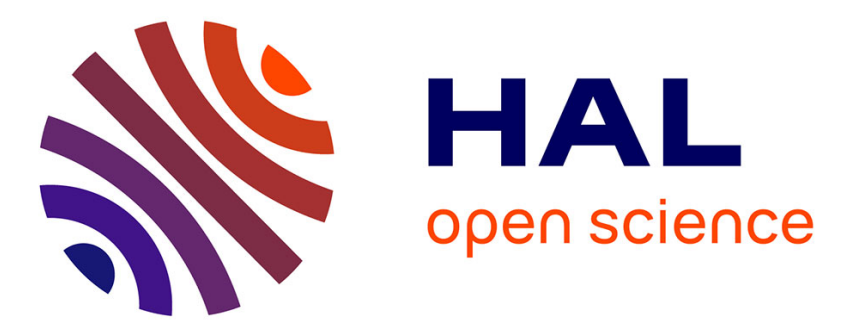

\title{
Hydrogen in beryllium oxide investigated by DFT: on the relative stability of charged-state atomic versus molecular hydrogen
}

\author{
E. Hodille, Y Ferro, Z A Piazza, C. Pardanaud
}

\section{- To cite this version:}

E. Hodille, Y Ferro, Z A Piazza, C. Pardanaud. Hydrogen in beryllium oxide investigated by DFT: on the relative stability of charged-state atomic versus molecular hydrogen. Journal of Physics: Condensed Matter, 2018, 30 (30), pp.305201. 10.1088/1361-648X/aacd86 . hal-02112845

\section{HAL Id: hal-02112845 \\ https://hal.science/hal-02112845}

Submitted on 27 Apr 2019

HAL is a multi-disciplinary open access archive for the deposit and dissemination of scientific research documents, whether they are published or not. The documents may come from teaching and research institutions in France or abroad, or from public or private research centers.
L'archive ouverte pluridisciplinaire HAL, est destinée au dépôt et à la diffusion de documents scientifiques de niveau recherche, publiés ou non, émanant des établissements d'enseignement et de recherche français ou étrangers, des laboratoires publics ou privés. 


\title{
Hydrogen in beryllium oxide investigated by DFT: on the relative stability of charged-state atomic versus molecular hydrogen
}

\author{
E.A. Hodille, Y. Ferro ${ }^{*}$ Z. A. Piazza, C. Pardanaud \\ Aix Marseille Univ, CNRS, PIIM, Marseille, France \\ *Corresponding author: yves.ferro@unv-amu.fr
}

\section{Abstract}

The behavior of hydrogen in perfect wurtzite beryllium oxide is herein investigated by means of electronic structure calculations based on Density functional theory. The formation energies of the following set of states of hydrogen $\left(\mathrm{H}^{0}, \mathrm{H}^{+}, \mathrm{H}^{-}, \mathrm{H}_{2}, \mathrm{H}_{2}{ }^{+}, \mathrm{H}_{2}{ }^{-}\right)$are computed and their solubility is established as a function of temperature and pressure with emphasis given to conditions relevant for hydrogen-implanted materials. It is found that all magnetic states $\mathrm{H}^{0}, \mathrm{H}_{2}{ }^{+}, \mathrm{H}_{2}^{-}$are unstable, while the relative stability of the non-magnetic states depends on the thermodynamic conditions: $\mathrm{H}_{2}$ prevails above temperatures around $900 \mathrm{~K}$ at standard pressure, which is the lowest temperature in experiments measuring the diffusion coefficient of hydrogen in wurtzite beryllium oxide. Under hydrogen implantation, the total concentration of hydrogen is fixed by the implantation source; it is found that molecular hydrogen prevails starting from a very low total concentration in hydrogen (as low as $10^{-40}$ at.fr.). Finally, the diffusion coefficient of $\mathrm{H}_{2}$ in beryllium oxide is calculated and the results are compared with previous experimental data. 


\section{Introduction}

Beryllium (Be) is one of the major plasma facing materials in current tokamaks like JET [1, 2] and the ITER tokamak $[3,4]$ which is currently being built. Pure beryllium is particularly easy to oxidize and indeed was observed in the JET tokamak. Consequently, an oxide layer is expected to form on top of the plasma facing components of ITER. It follows naturally that the retention, permeation and outgassing of hydrogen isotopes with beryllium oxide are key considerations for plasma control and overall safety of operating these fusion reactors. The administrative limit on the amount of tritium in the vacuum chamber of ITER is currently fixed to 700g. Assuming that about $1 \mathrm{~g}$ of tritium will be retained after each plasma shot, this limit will be reached after $\approx 700$ shots, corresponding to only two months of normal operation [5]. Thus the retention, permeation and outgassing of hydrogen in fusion materials is an area of intense investigation, both by theory and experiment.

Calculations of hydrogen retention in fusion materials have been carried out based on rateequations $[6,7,8,9,10,11,12,13]$, Kinetic-Monte Carlo [14, 15, 16], Molecular Dynamics [16, $17,18,19]$ and density functional theory (DFT) $[20,21,22,23,24,25,26,27,28]$. Results from DFT calculations offer valuable atomic-scale insights and provide the starting point of multiscale approaches. Such a DFT investigation on beryllium oxide requires at first to determine the stable interstitial states of hydrogen among $\mathrm{H}^{0}, \mathrm{H}^{+}, \mathrm{H}^{-}, \mathrm{H}_{2}, \mathrm{H}_{2}{ }^{+}, \mathrm{H}_{2}{ }^{-}$in finite temperature and pressure conditions relevant to laboratory experiments. Once established, we investigated the diffusion properties of hydrogen in $\mathrm{BeO}$ and compare our results with existing experimental measurements.

A previous DFT investigation by Marinopoulos et al. [21] established the formation of hydrogen in its neutral $\mathrm{H}^{0}$, donor $\mathrm{H}^{+}$and acceptor $\mathrm{H}^{-}$forms in $\mathrm{BeO}$. The neutral form is less stable than its 
charged states over the full band-gap region, and the pinning level $\varepsilon(+/-)$ was found more or less in the middle of the band gap. As a consequence, hydrogen displays an amphoteric character similar to its behavior in many large band semiconductors $[29,30]$. In many oxides indeed, $\mathrm{H}^{+}$ and $\mathrm{H}^{-}$are the lowest energy states for Fermi energies in the lower part and upper part of the band gap, respectively. On the contrary, neutral atomic hydrogen is rarely the lowest energy state, but previous theoretical work shows that in $\mathrm{ZnO}[31]$ and $\mathrm{GaN}[32,33]$ molecular hydrogen displays the lowest formation energy per hydrogen at the pinning level $\varepsilon(+/-)$. The pinning level is located above the conduction band in $\mathrm{ZnO}$, and consequently hydrogen only exists in its donor $\mathrm{H}^{+}$form, yet in $\mathrm{GaN}$, the pinning level lies in the mid-band-gap region in both wurtzite and zinc-blende structures [32, 33]. In beryllium oxide, molecular hydrogen has not been investigated yet to our knowledge.

The diffusion coefficient of hydrogen in $\mathrm{BeO}$ was previously assessed experimentally. MacaulayNewcombe et al. [34] fitted thermal desorption spectrometry (TDS) data of deuterium implanted in $\mathrm{BeO}$ with the TMAP rate-equation code and found a diffusion barrier of $2.1 \mathrm{eV}$. Fowler et al. [35] measured the release rate of tritium implanted in single crystal and sintered $\mathrm{BeO}$ samples in a range of temperature from $800 \mathrm{~K}$ to $1500 \mathrm{~K}$. They established a barrier of diffusion of $2.3 \pm 0.3$ $\mathrm{eV}$ for tritium in $\mathrm{BeO}$, in good correspondence with Macaulay-Newcombe et al. From the modelling side, based on DFT calculations by Allouche et al. [20], the diffusion of hydrogen in $\mathrm{BeO}$ was found anisotropic with activation barriers in the range of $0.7 \mathrm{eV}$, which is well below the experimental value. This discrepancy is probably the consequence that only neutral atomic hydrogen was considered in this previous work. As a consequence, the diffusion coefficient of molecular hydrogen in beryllium oxide is revisited in the present paper. 
The work herein addresses the need of an atomic-scale investigation which models atomic and molecular hydrogen in its neutral and charged states $\left(\mathrm{H}^{0}, \mathrm{H}^{+}, \mathrm{H}^{-}, \mathrm{H}_{2}, \mathrm{H}_{2}{ }^{+}, \mathrm{H}_{2}{ }^{-}\right)$in the context of a perfect wurtzite beryllium oxide environment. The remainder of the paper is organized as follows: section 2 presents the methodology used in this work. Section 3 reports on the different states (atomic and molecular, neutral and charged) of hydrogen in $\mathrm{BeO}$; their relative stabilities are determined at finite temperature and pressure with emphasis given to experimental conditions relevant to diffusion measurements and hydrogen-implanted materials. In section $\mathbf{4}$, the diffusion coefficient of hydrogen in beryllium oxide is derived and compared with experimental measurements from the literature. Furthermore, as Raman spectroscopy is well adapted to investigate the many chemical bonds that beryllium establishes with oxygen and hydrogen [36, 37], vibrational frequencies at the gamma point are also computed to assist in the assignment of future Raman spectroscopy measurements.

\section{Method}

The calculations reported here were performed using spin-polarized DFT with a plane-wave basis set as implemented in the Quantum Espresso code [38]. We used the GGA-PBE exchange and correlation functional [39] along with corresponding ultra-soft pseudo-potentials [40] to model the ionic cores of beryllium, oxygen and hydrogen atoms.

$\mathrm{BeO}$ crystallizes in the hexagonal wurtzite structure at room temperature and standard pressure; it is shown in Figure 1. The lattice parameters were calculated as $\mathbf{a}=2.766 \AA$ and $\mathbf{c}=4.496 \AA$; these are about $4 \%$ higher than the experimental values: $\mathbf{a}=2.698 \AA$ and $\mathbf{c}=4.378 \AA$ [41]. Such a small overestimation is a general trend of the GGA functionals as the PBE [42] herein used. The $\frac{c}{a}$ parameter is within $0.1 \%$ of the experimental value, which demonstrates the consistency of 
the calculated values. The unit-cell contains two beryllium and two oxygen atoms; their coordinates in crystalline units are $\left(\frac{1}{3} \frac{2}{3} 0\right)$ and $\left(\frac{2}{3} \frac{1}{3} \frac{1}{2}\right)$ for the beryllium atoms and $\left(\frac{1}{3} \frac{2}{3} \mathrm{z}\right)$ and $\left(\frac{2}{3} \frac{1}{3}\right.$ $\frac{1}{2}+z$ ) for the oxygen atoms, where $\mathrm{z}$ is the internal coordinate of wurtzite. $\mathrm{z}$ is equal to $0.375 \mathrm{in}$ perfect wurtzite, in which case each oxygen atom is in the center of a tetrahedron formed by its four nearest-neighbors beryllium atoms. We calculated $\mathrm{z}=0.377$ in excellent agreement with the experimental value of $\mathrm{z}=0.378$ measured by Vidal-Valat et al. [43].

The working supercell was built as a $3 \times 3 \times 3$ repetition of the $\mathrm{BeO}$ unit cell and contains a total of 108 atoms. Cutoff energies of $52 \mathrm{Ry}(707 \mathrm{eV})$ and $416 \mathrm{Ry}(5658 \mathrm{eV})$ were used for the truncation of the expansion of the wave functions and the electronic density respectively. A $6 \times 6 \times 6 \mathrm{k}$-point mesh was used to sample the Brillouin zone of to the supercell. Both the position of the atoms and the unit-cell were geometrically optimized to a force convergence threshold of $1 \times 10^{-4}$ $\mathrm{eV} / \AA$.

The calculated band-gap is $7.23 \mathrm{eV}$, in good agreement with the one found by Marinopoulos et al. [21] at $7.41 \mathrm{eV}$ using the PBE functional; it is nevertheless well below the experimental value of $10.6 \mathrm{eV}$ [44]. This underestimation is a well-established failure of DFT and is known as the delocalization error, which reflects the erroneous convex behavior of the electronic energy as a function of the fractional charge of the system [45]. Hartree-Fock (HF) exchange has the opposite characteristics, which explain why hybrid functionals benefit from error cancellation and perform better with band-gaps. A common practice is to tune the part of HF exchange in hybrid functionals [46, 47] up to the point where the correct band gap is obtained; this does not guarantee that the other properties of the system are improved and could even have the opposite effect. Marinopoulos [21] used the HSE functional with $36 \%$ of HF exchange to restitute the correct band-gap value in $\mathrm{BeO}$. In the present study, we used the PBE functional for 
computational efficiency and refer to the results of Marinopoulos [21] for comparison with the correct band-gap value when necessary.

The formation energy of $\mathrm{j}$ hydrogens atoms of charge $\mathrm{q}$ in beryllium oxide was calculated according to:

$$
E_{f}\left(H_{j}, q\right)=E_{B e O+j H}^{D F T}-E_{B e O}^{D F T}-j \mu_{H}+q\left(\mu_{e}+E_{V B M}\right)
$$

Where $\mathrm{E}_{\mathrm{BeO}+\mathrm{j} \cdot \mathrm{H}}^{\mathrm{DFT}}$ is the total energy of the $\mathrm{BeO}$ supercell with hydrogen, $\mathrm{E}_{\mathrm{BeO}}^{\mathrm{DFT}}$ is the total energy of the perfect $\mathrm{BeO}$ supercell, $\mu_{H}=\frac{1}{2} \mathrm{E}_{\mathrm{H}_{2}}^{\mathrm{DFT}}$ is the chemical potential of $\mathrm{H}$ taken as to half the total energy of an isolated $\mathrm{H}_{2}$ molecules calculated in a box of dimensions $20 \times 20 \times 25 \AA^{3}$, $\mu_{\mathrm{e}}$ is the chemical potential of the reservoir with which the electrons are exchanged and $E_{\mathrm{VBM}}$ is the position of the valence band maximum. Thus, $\mu_{\mathrm{e}}+\mathrm{E}_{\mathrm{VBM}}$ gives the reference energy for the Fermi-level positions in the gap. A correction to the formation energies was also added in order to account for the electrostatic interactions of the defect with its periodically generated images. We did the same as in the paper of Marinopoulos et al. [21] and used the Freysold's code [48] based on the first-order correction due to Makov and Payne [49] with the general formalism described in Ref [47]. The magnitude of the correction to apply is equal to $0.40 \mathrm{eV}$ using the experimental static dielectric tensor $\left(\kappa_{a}^{\prime}=6.87\right.$ and $\left.\kappa_{c}^{\prime}=7.74[50]\right)$.

Vibrational properties were computed with Density Functional Perturbation Theory (DFPT) [51]. The Zero Point Energy (ZPE) correction was neglected due to the computational expense of the procedure. Vibrational properties were computed at the $\Gamma$ point of the most stable solution sites for hydrogen. The aim was to provide Raman spectroscopy with frequencies to assist in identifying hydrogenated structures in beryllium oxide, this technique being sensitive to the $\Gamma$ point only [52]. 
The Nudged Elastic Band (NEB) method [53, 54] was used to determine the activation energies for the diffusion using five to seven images. The NEB calculations were considered converged once the norm of the forces orthogonal to the path are less than $0.01 \mathrm{eV} / \mathrm{A}$.

\section{Hydrogen at interstitial sites in $\mathrm{BeO}$}

\section{1 . Neutral atomic hydrogen $\left(H^{0}\right)$}

Three distinct interstitial sites correspond to energy minima for atomic hydrogen in beryllium oxide. The most stable, or ground state, is of octahedral symmetry (Oh). In the ground state, the hydrogen atom adopts a position which is equidistant from the six surrounding oxygen atoms. (Figure 1). The two others exhibit tetrahedral symmetry and will be referred to as $\operatorname{Td}_{1}$ and $\operatorname{Td}_{2}$.

In the Oh site, the formation energy is $\mathrm{E}_{\mathrm{f}}^{\mathrm{Oh}}(1 \mathrm{H})=3.84 \mathrm{eV}$ (Table 1), while it was previously reported to $\mathrm{E}_{\mathrm{f}}^{\mathrm{Oh}}(1 \mathrm{H})=4.36 \mathrm{eV}$ in the literature [20]. The difference in energy could be the result of our geometric optimization procedure in which both the unit-cell parameters and atomic positions were relaxed. The two tetrahedral sites $\mathrm{Td}_{1}$ and $\mathrm{Td}_{2}$ shown in Figure 1 lead to formation energies of $\mathrm{E}_{\mathrm{f}}^{\mathrm{Td}_{1}}(1 \mathrm{H})=4.38 \mathrm{eV}$ and $\mathrm{E}_{\mathrm{f}}^{\mathrm{Td}_{2}}(1 \mathrm{H})=4.86 \mathrm{eV}$.

For each of the three distinct adsorption sites, the total magnetization generated by adding one hydrogen atom in $\mathrm{BeO}$ is $1.00 \mu_{\mathrm{B}} /$ cell. This corresponds to a free radical of high chemical reactivity. Figure 1 displays the spin density of hydrogen in the $\mathrm{Oh}$ site; it is of spherical symmetry, suggesting that no chemical bonding exists between the hydrogen radical and its environment. Indeed, the vibrational frequencies calculated at the gamma point $\left(1129 \mathrm{~cm}^{-1}\right.$ (x2) and $1071 \mathrm{~cm}^{-1}$ ) are much lower than the one expected for an $\mathrm{O}-\mathrm{H}$ bond around $3600 \mathrm{~cm}^{-1}$. 


\begin{tabular}{c|llcc}
\multicolumn{2}{c}{} & $E_{f}(j H)(\mathrm{eV})$ & Total magnetization $\left(\mu_{B} /\right.$ cell $)$ \\
\hline$j=1$ & $\mathrm{H}^{0}$ & 3.84 & 1.00 \\
& $\mathrm{H}^{+}$ & 3.31 & 0.00 \\
& $\mathrm{H}^{-}$ & 3.31 & 0.00 \\
\hline & $\mathrm{H}_{2}$ & 3.96 & 0.00 \\
& $\mathrm{H}_{2}^{+}$ & 7.85 & 1.00 \\
& $\mathrm{H}_{2}^{-}$ & 7.07 & 1.00
\end{tabular}

Table 1. Formation energy of interstitial hydrogen defects in $\mathrm{BeO}$. $\mathrm{E}_{\mathrm{f}}$ is given per $\mathrm{H}_{\mathrm{j}}^{\mathrm{q}}$ defect. Only the most stable configuration for each defect is considered. For charged states, the formation energy is given at the pinning level. 

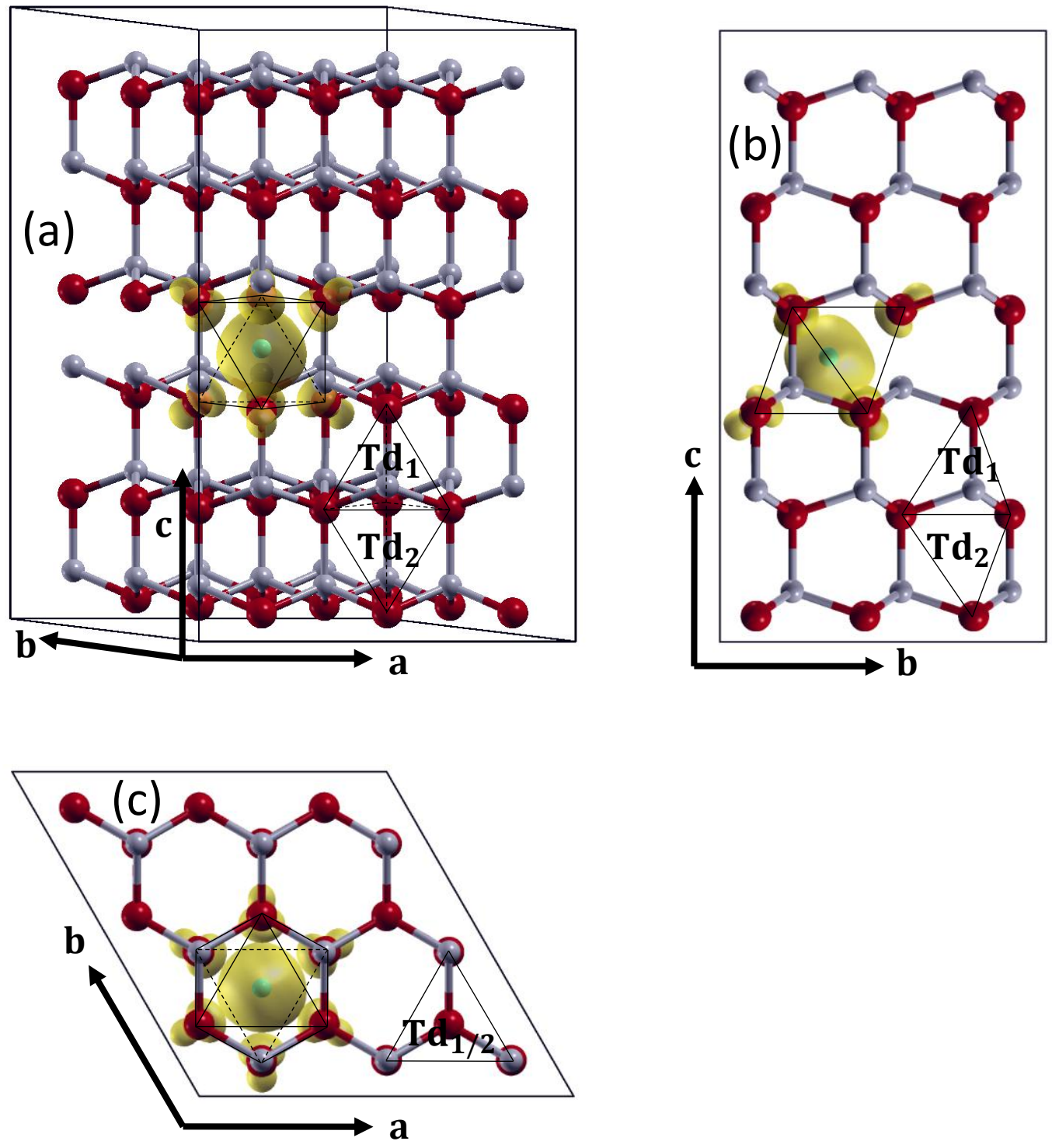

Figure 1. The most stable configuration of a neutral hydrogen interstitial atom in the wurtzite structure of $\mathrm{BeO}$. (a) Perspective view, (b) projected view on the (b, c) plane, (c) projected view on the $(\mathbf{a}, \mathbf{b})$ plane. The red balls represent the position of the oxygen atoms, the grey ones those of the beryllium atoms and the blue balls represent the location of the interstitial hydrogen atom. The octahedral site $(\mathrm{Oh})$ formed by $6 \mathrm{O}$ atoms is depicted by black lines surrounding the hydrogen atom. The two tetrahedral sites $\left(\mathrm{Td}_{1}\right.$ and $\left.\mathrm{Td}_{2}\right)$ are also shown with black lines. Spin densities are plotted with a $0.004 \mathrm{bohr}^{-3}$ iso-surface value. 


\section{2. Atomic hydrogen in charged states $\left(H^{9}\right)$}

Hydrogen in its positively charged state $\mathrm{H}^{+}$displays no magnetic moment (i.e, the absolute magnetization in the unit cell is zero). Marinopoulos et al [21] showed that four configurations exist for $\mathrm{H}^{+}$in $\mathrm{BeO}$. The ground state configuration is approximately half an electron-Volt lower in energy than the three other ones. The ground state configuration is shown in Figure 2a: an O-H bond is formed parallel to the $\mathbf{c}$ axis with a bond length of $0.97 \AA$ close to the one in $\mathrm{H}_{2} \mathrm{O}$ [55]. The stretching frequency is $3732 \mathrm{~cm}^{-1}$ for $\mathrm{O}-\mathrm{H}\left(2709 \mathrm{~cm}^{-1}\right.$ for O-D), comparable to the stretching frequencies of $\mathrm{H}_{2} \mathrm{O}$ at $3585 \mathrm{~cm}^{-1}$ and $3506 \mathrm{~cm}^{-1}$. Similar results were found for $\mathrm{H}^{+}$in $\mathrm{ZnO}$ with the formation of an $\mathrm{O}-\mathrm{H}$ bond and a corresponding stretching frequency of $3680 \mathrm{~cm}^{-1}$ [31]. In its negatively charged state, $\mathrm{H}^{-}$exhibits no magnetic moment. It adopts the same position as neutral hydrogen and resides in an interstitial site of high symmetry as shown in Figure $2 b$. The low vibrational frequencies computed at the gamma point confirm that no chemical bond is

formed; they are $1844(\mathrm{x} 2) \mathrm{cm}^{-1}$ and $1534 \mathrm{~cm}^{-1}$ for hydrogen $\left(1329(\mathrm{x} 2) \mathrm{cm}^{-1}\right.$ and $1124 \mathrm{~cm}^{-1}$ for deuterium), far below the ones found for $\mathrm{H}^{+}$. 

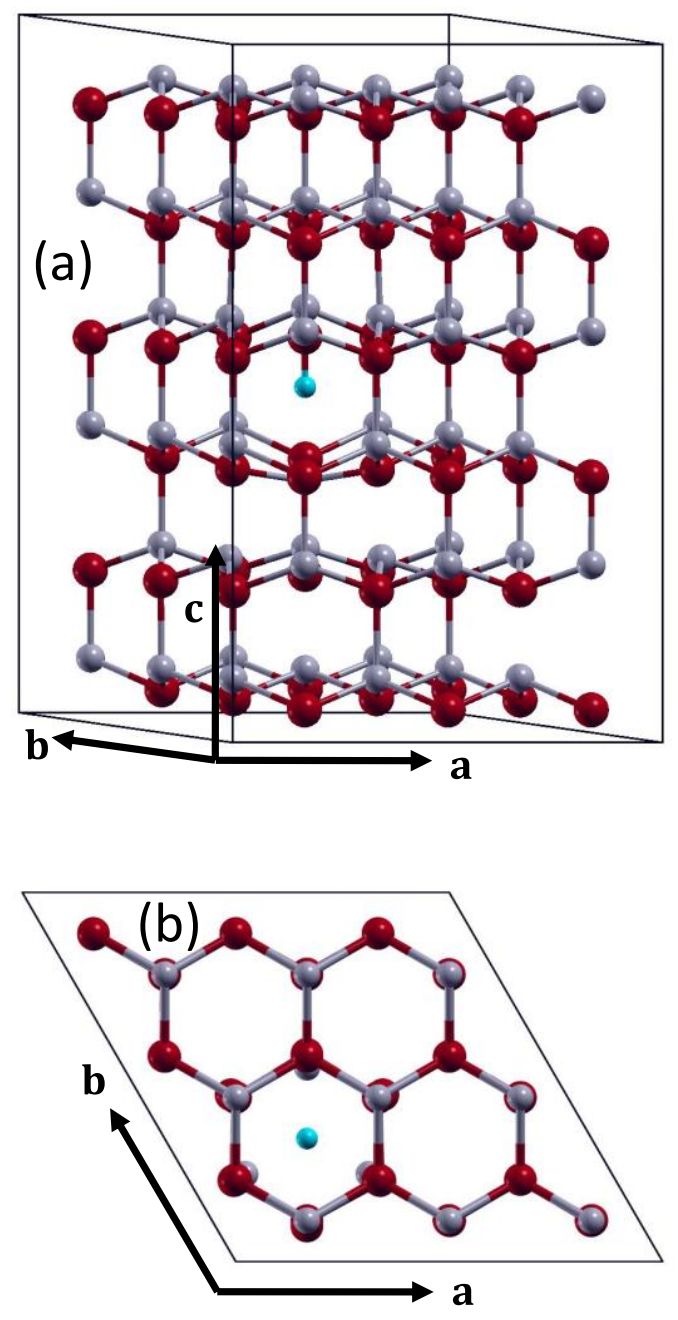

Figure 2: Most stable configuration for (a) $\mathrm{H}^{+}$perspective view and (b) $\mathrm{H}^{-}$projected view on the (b, c) plane.

\section{3. Molecular hydrogen $\left(\mathrm{H}_{2}\right)$}

Molecular hydrogen in $\mathrm{BeO}$ displays no magnetic moment. It resides in the center of the Oh site as for $\mathrm{H}_{2}$ in wurtzite $\mathrm{GaN}$ [33], oriented in the c direction as shown in Figure 3. The $\mathrm{H}-\mathrm{H}$ distance in $\mathrm{BeO} \mathrm{d}_{\mathrm{H}-\mathrm{H}}=0.723 \AA$ is a little bit shorter than in the free molecule $(0.752 \AA)$, indicating covalent bonding. The phonon frequency calculated at the gamma point is $4610 \mathrm{~cm}^{-1}$ for $\mathrm{H}_{2}$ (3259 $\mathrm{cm}^{-1}$ for $\mathrm{D}_{2}$ ), a little bit higher than the one calculated for a free $\mathrm{H}_{2}$ molecule in an empty 
lattice at $4326 \mathrm{~cm}^{-1}\left(3061 \mathrm{~cm}^{-1}\right.$ for $\left.\mathrm{D}_{2}\right)$. This increase in frequency agrees well with the shortening of the bond length due to the constraints of the $\mathrm{BeO}$ environment [52].
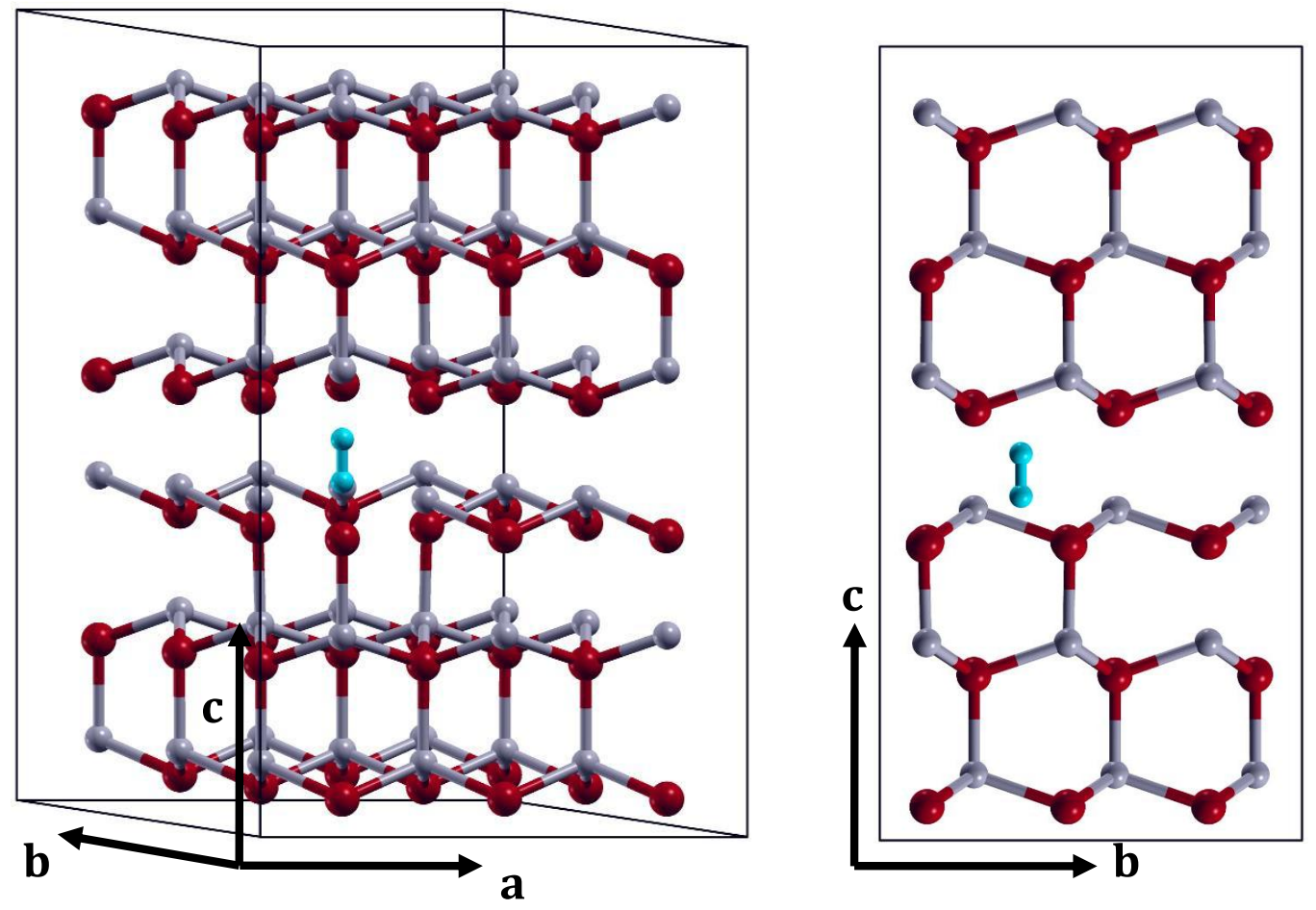

Figure 3: Most stable configuration for $\mathrm{H}_{2}$ aligned along the $\mathrm{c}$ axis: (a) perspective view and (b) projected view on the $(\mathbf{b}, \mathbf{c})$ plane.

The binding energy, calculated as the difference in energy between a $\mathrm{H}_{2}$ molecule and two $\mathrm{H}^{0}$ atoms, is $3.72 \mathrm{eV}$ per molecule, not far from the binding energy in the gas phase $4.52 \mathrm{eV}$. Alternatively, and following Limpijumnong and Van de Walle [33], the binding energy defined as the energy difference between $\mathrm{H}_{2}$ and the sum of $\mathrm{H}^{+}$and $\mathrm{H}^{-}$at the pinning resulting from $\mathrm{H}^{+}+$ $\mathrm{H}^{-} \rightarrow \mathrm{H}_{2}$ is $2.66 \mathrm{eV}$. Both results emphasize the likelihood of $\mathrm{H}_{2}$ to be formed in $\mathrm{BeO}$.

\section{4. Formation energies of hydrogenic defects in $\mathrm{BeO}$}

The formation energy of atomic hydrogen in its neutral and charged states were calculated according to equation (1) and plotted in Figure $4 . \mathrm{H}^{+}$and $\mathrm{H}^{-}$displays the lowest formation energy 
close to the valence band and conduction band, respectively. Neutral hydrogen is never the most stable state over the full band-gap. Similar results were reported by Marinopoulos et al [21]. The pinning level lies in the middle of the band-gap, which we computed as $7.2 \mathrm{eV}$; this is smaller than the experimental value at $10.6 \mathrm{eV}$. Marinopoulos et al [21] adjust the correct band-gap value with the HSE functional. The ratio of the pinning level to the band-gap width is $\varepsilon(+/-) / \Delta \mathrm{E}_{\mathrm{band}-\mathrm{gap}}=$ 0.57 in both works, which insure the pinning level $\varepsilon(+/-)$ effectively lies in the middle of the band gap.

The formation energy of $\mathrm{H}_{2}$ is also calculated according to equation (1). Nevertheless, as energy is an extensive property, it has to be compared with respect to the same amount of substance. Following, Neugebauer and Van de Walle [56], Wright [32], Limpijumnong and Van de Walle [33] and Myers et al [57], we plotted $\mathrm{E}_{\mathrm{f}}$ per $\mathrm{H}$ atom in Figure 4. The formation energy (per $\mathrm{H}$ atom) of $\mathrm{H}_{2}$ is lower than those of $\mathrm{H}^{+}$and $\mathrm{H}^{-}$when the Fermi level lies near the middle of the bad gap, which is where the Fermi level of intrinsic semi-conductor is [58]. This result reflects the strong binding energy of $\mathrm{H}_{2}$ in $\mathrm{BeO}$ as discussed in section 3.3. 


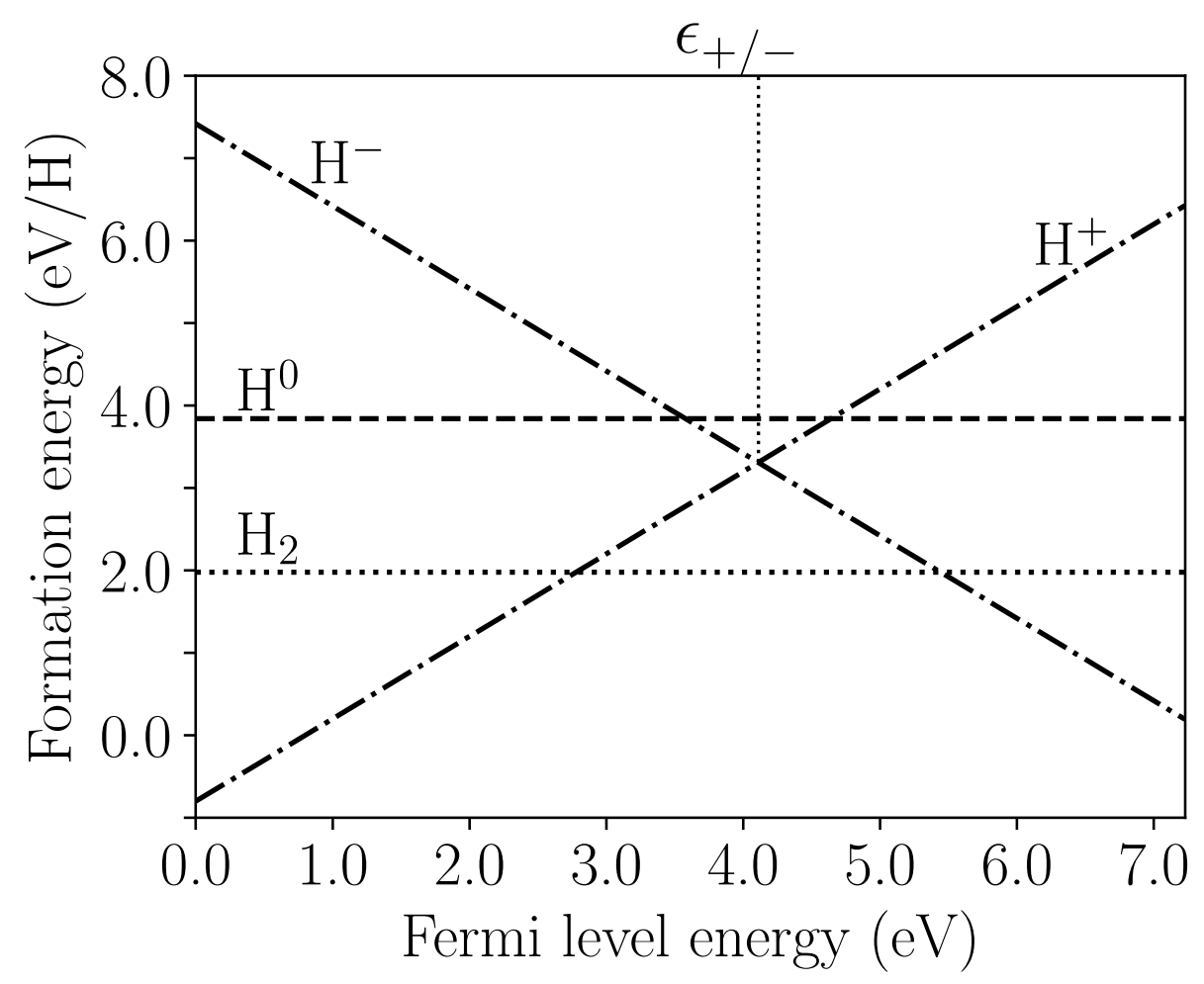

Figure 4: Formation energy (par hydrogen atom) versus the Fermi level for hydrogen in its neutral and charge states. The reference energy for the Fermi level is set at the valence band edge.

\section{5. On the concentration and stability of hydrogenic defects in BeO}

At finite temperature and pressure, the relevant quantity to determine the stability of a defects is the Gibbs free energy of formation $g_{f}=h_{f}-T s_{f}$ [46]. As mentioned by R. Kircheim [59], the major contribution to the entropy change in dissolution of hydrogen in a solid results from the loss of the rotational and translational degrees of freedom of the $\mathrm{H}_{2}$ molecule relative to the gas phase. The same applies to the enthalpy.

Assuming the $\mathrm{H}_{2}$ gas phase behaves like an ideal gas, the translational and rotational component to the enthalpy is simply $h_{\text {trans,rot }}=\frac{7}{2} \mathrm{kT}$, and it is $\mathrm{s}_{\mathrm{rot}}=\mathrm{k}_{\mathrm{B}}\left(1+\ln \left[\frac{8 \pi^{2} \mathrm{IkT}}{\sigma \mathrm{h}^{2}}\right]\right)$ and $\mathrm{s}_{\text {trans }}^{\circ}=$ $\mathrm{k}_{\mathrm{B}}\left(\frac{5}{2}+\ln \left[\frac{\mathrm{kT}}{\mathrm{P}^{\circ}}\left(\frac{2 \pi \mathrm{m} \mathrm{kT}}{\mathrm{h}^{2}}\right)^{\frac{3}{2}}\right]\right)$ for the entropy under standard conditions at $\mathrm{P}^{\circ}$. In these expressions, 
$\mathrm{m}$ and $\mathrm{I}$ are the mass and inertia momentum of the $\mathrm{H}_{2}$ molecule, while $\sigma=2$ for a homonuclear diatomic molecule.

\subsubsection{Atomic fraction of hydrogen at finite pressure and temperature}

Considering the different charge states $q$ of atomic hydrogen, the standard Gibbs free energy corresponding to the $\mathrm{BeO}+\frac{1}{2} \mathrm{H}_{2} \rightarrow\left(\mathrm{H}^{\mathrm{q}}\right.$ in $\left.\mathrm{BeO}\right)$ transformation is:

$$
\mathrm{g}_{\mathrm{f}}^{\circ}\left(\mathrm{H}^{\mathrm{q}}\right)=\left(\mathrm{E}_{\mathrm{f}}\left(\mathrm{H}^{\mathrm{q}}\right)-\frac{1}{2} \mathrm{~h}_{\text {tran,rot }}^{\mathrm{H}_{2}}\right)+\frac{1}{2} \mathrm{~T} \cdot \mathrm{s}_{\text {tran,rot }}^{\mathrm{H}_{2}}
$$

where $\mathrm{E}_{\mathrm{f}}\left(\mathrm{H}^{\mathrm{q}}\right)$ is reported at the pinning level in Table 1 . The corresponding solubility $\mathrm{x}_{\mathrm{H}^{\mathrm{q}}}$ per $\mathrm{BeO}$ unit is:

$$
\mathrm{x}_{\mathrm{H}^{\mathrm{q}}}=\sqrt{\frac{\mathrm{P}}{\mathrm{P}^{\circ}}} \cdot \exp \left(-\frac{\mathrm{g}_{\mathrm{f}}^{\circ}\left(\mathrm{H}^{\mathrm{q}}\right)}{\mathrm{kT}}\right)
$$

Considering the different charge states of molecular hydrogen, the standard Gibbs free energy corresponding to the $\mathrm{BeO}+\mathrm{H}_{2} \rightarrow\left(\mathrm{H}_{2}{ }^{\mathrm{q}}\right.$ in $\left.\mathrm{BeO}\right)$ transformation is :

$$
\mathrm{g}_{\mathrm{f}}^{\circ}\left(\mathrm{H}^{\mathrm{q}}\right)=\left(\mathrm{E}_{\mathrm{f}}\left(\mathrm{H}^{\mathrm{q}}\right)-\mathrm{h}_{\text {tran,rot }}^{\mathrm{H}_{2}}\right)+\mathrm{T} \cdot \mathrm{s}_{\text {tran,rot }}^{\mathrm{H}_{2}}
$$

Where $\mathrm{E}_{\mathrm{f}}\left(\mathrm{H}_{2}^{\mathrm{q}}\right)$ is given per molecule and is reported at the pinning level in Table 1. The solubility of $\mathrm{H}_{2}{ }^{\mathrm{q}} \mathrm{x}_{\mathrm{H}_{2}^{\mathrm{q}}}$ expressed in $\mathrm{H}_{2}{ }^{\mathrm{q}}$ per $\mathrm{BeO}$ units is:

$$
\mathrm{x}_{\mathrm{H}_{2}^{\mathrm{q}}}=\frac{\mathrm{P}}{\mathrm{P}^{\mathrm{o}}} \cdot \exp \left(-\frac{\mathrm{g}_{\mathrm{f}}\left(\mathrm{H}_{2}^{\mathrm{q}}\right)}{\mathrm{kT}}\right)
$$

The solubility (or atomic fraction) of all $\mathrm{H}_{\mathrm{j}}{ }^{\mathrm{q}}$ states are plotted in Figure 5 versus the inverse of the temperature for a Fermi level at the pinning level and under standard pressure $\mathrm{P}^{\circ}$. At the pinning level, $\mathrm{g}_{\mathrm{f}}\left(\mathrm{H}^{+}\right)=\mathrm{g}_{\mathrm{f}}\left(\mathrm{H}^{-}\right)$and consequently the concentration of both species is the same.

The results are as follows: at room temperature and at standard pressure, the atomic fraction of hydrogen in any form is negligible. Over the whole range of temperature here considered, the atomic fraction of $\mathrm{H}_{2}{ }^{+}$and $\mathrm{H}_{2}{ }^{-}$that induces magnetic states are clearly negligible as compared to the other states of hydrogen. The atomic fraction of $\mathrm{H}^{0}$ remains several orders of magnitude 
smaller than the concentration of $\mathrm{H}^{+/-}$as expected from Figure 4; again, $\mathrm{H}^{0}$ displays a magnetic state. The non-magnetic $\mathrm{H}_{2}$ and $\mathrm{H}^{+/-}$states are prevailing over the full range of temperature. Entropic effects favor the solubility of $\mathrm{H}_{2}$ against $\mathrm{H}^{+/-}$. Consequently, $\mathrm{H}_{2}$ becomes the predominant species at temperatures around $900 \mathrm{~K}$ and above; $900 \mathrm{~K}$ corresponds to the lower end of the temperature domain where the diffusion coefficient is experimentally established [34] [35]. Thus our calculations predict that hydrogen exist in its molecular form under experimental conditions in which the diffusion coefficient was measured.

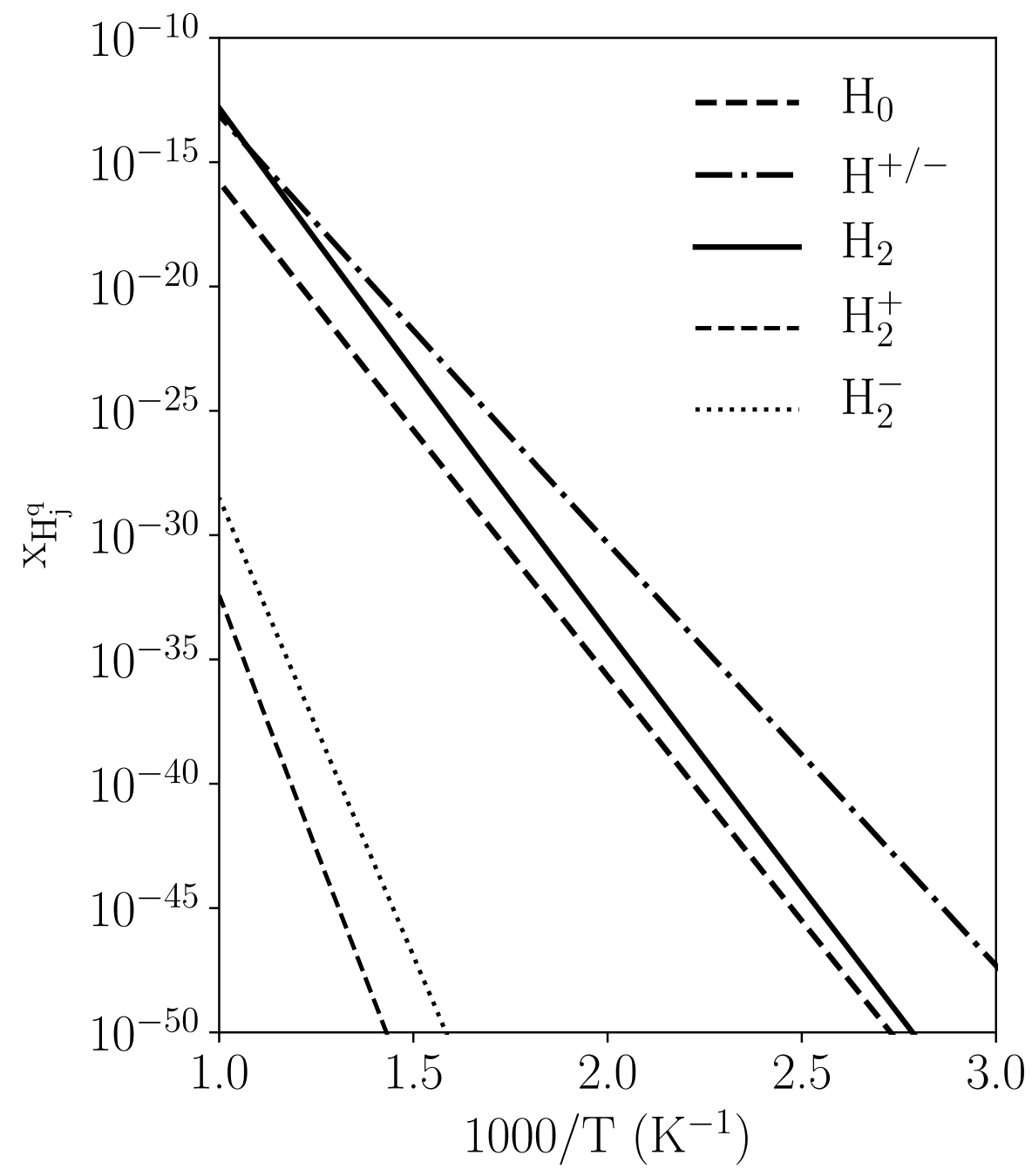


Figure 5: Solubility (or atomic fraction) $\mathrm{x}_{\mathrm{H}_{\mathrm{j}}}$ of all of the various states $\mathrm{H}_{\mathrm{j}}{ }^{\mathrm{q}}$ herein investigated plotted versus $1000 / \mathrm{T} . \mathrm{x}_{\mathrm{H}_{\mathrm{j}}^{\mathrm{q}}}$ is given in $\mathrm{H}_{\mathrm{j}}^{\mathrm{q}}$ per $\mathrm{BeO}$ unit.

\subsubsection{Equilibrium of $\mathrm{H}^{+/-}$and $\mathrm{H}_{2}$ at a fixed concentration of hydrogen}

The results above apply when an equilibrium exists between $\mathrm{H}_{2}$ in the gas phase and hydrogen in BeO. However, in hydrogen-implanted materials, there is no gas phase and the total concentration of hydrogen in the material (i.e its chemical potential), is fixed by the implantation flux. Since the prevailing states at the pinning level are $\mathrm{H}^{+/-}$and $\mathrm{H}_{2}$, we focused on the $\mathrm{H}^{+}+\mathrm{H}^{-} \leftrightarrow$ $\mathrm{H}_{2}$ equilibrium in $\mathrm{BeO}$ depending on the total fraction $\mathrm{x}_{\text {tot }}$ of hydrogen implanted into the material. It is to be noted that the total concentration could also be fixed by a given pressure of hydrogen in equilibrium with $\mathrm{BeO}$. An increase in pressure will lead to an increase in concentration. In either case, at the pinning level, $\mathrm{x}_{\mathrm{H}^{+}}=\mathrm{x}_{\mathrm{H}^{-}}=\mathrm{x}_{\mathrm{H}^{+/-}}$and $\mathrm{E}_{\mathrm{f}}\left(\mathrm{H}^{+}\right)=\mathrm{E}_{\mathrm{f}}\left(\mathrm{H}^{-}\right)=$ $\mathrm{E}_{\mathrm{f}}\left(\mathrm{H}^{+/-}\right)$; the equilibrium consequently writes:

$$
\frac{\mathrm{x}_{\mathrm{H}_{2}}}{\mathrm{x}_{\mathrm{H}^{+/-}}^{2}}=\exp \left(-\frac{\mathrm{g}_{\mathrm{f}}\left(\mathrm{H}_{2}\right)-2 \mathrm{~g}_{\mathrm{f}}\left(\mathrm{H}^{+/-}\right)}{\mathrm{kT}}\right)=\exp \left(-\frac{\mathrm{E}_{\mathrm{f}}\left(\mathrm{H}_{2}\right)-2 \mathrm{E}_{\mathrm{f}}\left(\mathrm{H}^{+/-}\right)}{\mathrm{kT}}\right)
$$

The fraction of $\mathrm{H}_{2}$ and $\mathrm{H}^{+/-}$are plotted in Figure 6 at a temperature of $300 \mathrm{~K}$ versus the total fraction of hydrogen $\mathrm{x}_{\text {tot }}$. The total fraction $\left(\mathrm{x}_{\mathrm{tot}}\right)$ spans from the solubility of hydrogen in $\mathrm{BeO}$ at standard pressure and room temperature up to the concentration typically found in implanted materials above $10^{-5}$ at.fr. 


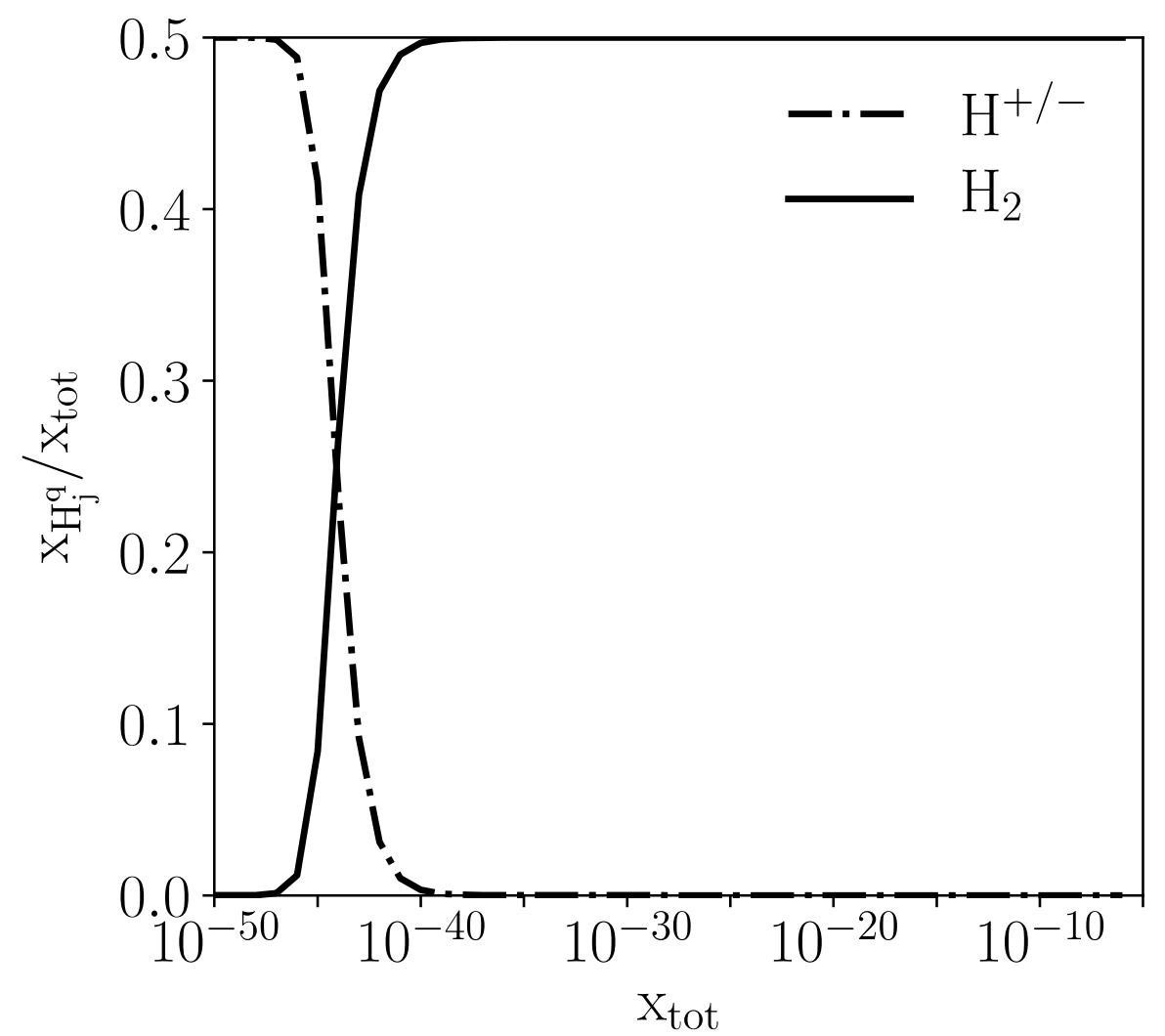

Figure 6: Fractions $\mathrm{x}_{\mathrm{H}_{\mathrm{j}}^{\mathrm{q}}}$ of $\mathrm{H}_{2}$ and $\mathrm{H}^{+/}$in $\mathrm{BeO}$ plotted versus the total fraction of hydrogen $\mathrm{x}_{\text {tot }}$ at $300 \mathrm{~K}$ and standard pressure. The maximum value is 0.5 in each case: for $\mathrm{H}^{+-}, \mathrm{H}$ is equally distributed between $\mathrm{H}^{+}$and $\mathrm{H}^{-}$. for $\mathrm{H}_{2}$ two atoms are necessary to firm a molecule.

As shown in Figure $6, \mathrm{H}_{2}$ becomes the predominant species starting from a very low total concentration in hydrogen around $10^{-40}$ at.fr. This is consistent with the energetic results presented in Figure 4, which displays the lowest formation energy for $\mathrm{H}_{2}$ at the pinning level. This is also consistent with Le Chatelier's principle since increasing the total concentration of hydrogen will shift the $\mathrm{H}^{+}+\mathrm{H}^{-} \leftrightarrow \mathrm{H}_{2}$ equilibrium forward. As explained by Wright [32], in the case of implanted materials, the hydrogen concentration can be large, and hydrogen becomes the dominant impurity leading to a non-negligible concentration of $\mathrm{H}_{2}$. Similar results were obtained by Myers et al. [57] who investigated the thermodynamic equilibrium of diverse states of 
hydrogen in GaN. The same conclusions were also drawn based on kinetic modellings by Myers and Wrirgth [60] still about hydrogen in GaN.

\section{6. Brief summary of section}

For the sake of clarity, we here make a brief summary of the previous results present in section 3 : (i) The most stable states for hydrogen are non-magnetic; they are $\mathrm{H}^{+}, \mathrm{H}^{-}$and the $\mathrm{H}_{2}$ molecule.

(ii) Molecular hydrogen is formed at the pinning level from two neutral interstitial atoms $\mathrm{H}^{0}$ or from the $\mathrm{H}^{+}$and $\mathrm{H}^{-}$charged states with a large binding energy. This is reflected by the formation energy per $\mathrm{H}$ atom plotted in Figure 4. (iii) The relative stability of $\mathrm{H}^{+}, \mathrm{H}^{-}$and $\mathrm{H}_{2}$ depends on the temperature and on the total concentration (or pressure) of hydrogen; above around $900 \mathrm{~K}_{2}$ is the stable species and is consequently the expected state for hydrogen in experiments dedicated to determine its diffusion coefficient in $\mathrm{BeO}$. Under hydrogen implantation conditions (or with increasing the pressure of the gas phase), $\mathrm{H}_{2}$ becomes the prevailing state starting from very low concentration at around $10^{-40}$ at.fr.

On the basis of these findings, the diffusion coefficient of hydrogen in its neutral molecular state $\mathrm{H}_{2}$ is investigated in the next section.

\section{Diffusion of molecular in BeO}

\section{1. Diffusion paths}

The energy paths for the migration of $\mathrm{H}_{2}$ were calculated using the nudges elastic band NEB technique. They are shown in Figure $7 \mathrm{a}$ along the c direction, and in Figure $7 \mathrm{~b}$ in a direction parallel to the basal plane along the $\mathbf{a}, \mathbf{b}$ or $\mathbf{a}+\mathbf{b}$ direction. None of the paths involve hydrogen passing through a tetrahedral (Td) site. Along the c direction, the distance between two 
interstitial sites is $\lambda_{\mathrm{c}}=\frac{\mathrm{c}}{2}=2.25 \AA$ A. The molecule remains oriented in the $\mathbf{c}$ direction and the energy barrier is $E_{D}^{c}\left(H_{2}\right)=1.81 \mathrm{eV}$. In the basal plane, the distance between two interstitial sites is $\lambda_{\|}=\mathrm{a}=2.77 \AA$. The $\mathrm{H}_{2}$ molecule, initially oriented in the $\mathbf{c}$ direction, rotates to align with the $\mathbf{a}+\mathbf{b}$ direction at mid-distance between the two Oh sites (corresponding to the saddle point/transition-state). The calculated migration energy is $\mathrm{E}_{\mathrm{D}}^{\|}\left(\mathrm{H}_{2}\right)=1.45 \mathrm{eV}$.
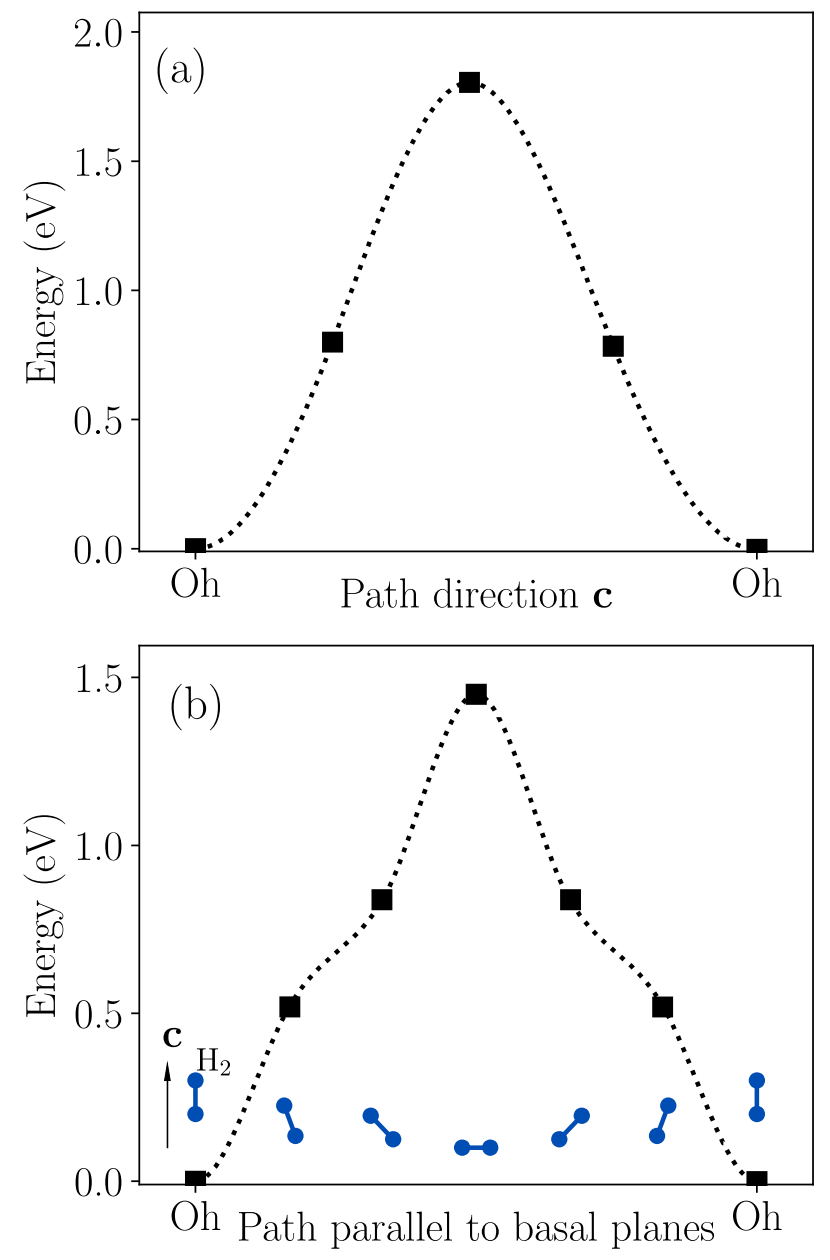

Figure 7. Energy profiles of the diffusion of $\mathrm{H}_{2}$ in wurtzite $\mathrm{BeO}$ (a) between two Oh sites in the c direction (5 images) and (b) in a path parallel to the basal planes ( 7 images) along the $\mathbf{a}, \mathbf{b}$ or $\mathbf{a}+\mathbf{b}$ directions. The rotation of the $\mathrm{H}_{2}$ molecule is sketched in blue. 


\section{2. Diffusion coefficient}

The diffusion coefficient $\mathrm{D}(\mathrm{T})\left(\mathrm{m}^{2} \mathrm{~s}^{-1}\right)$ of hydrogen in a material is usually given in the form of an Arrhenius law:

$$
\mathrm{D}(\mathrm{T})=\mathrm{D}_{0} \cdot \exp \left(-\frac{\mathrm{E}_{\mathrm{D}}}{\mathrm{kT}}\right)
$$

$\mathrm{k}$ is the Boltzmann constant, $\mathrm{T}$ the temperature and $\mathrm{E}_{\mathrm{D}}$ is the activation barrier for diffusion. We determine the diffusion coefficient on the basis of NEB calculations following the two paths discussed above. $\mathrm{D}_{0}\left(\mathrm{~m}^{2} \mathrm{~s}^{-1}\right)$ is a pre-exponential factor that is subsequently approximated using the Wert and Zener theory [61]:

$$
\mathrm{D}_{0}=n \alpha \mathrm{a}^{2} v
$$

where $n$ is the number of nearest neighbor interstitial position, $a(\mathrm{~m})$ the lattice constant, $v\left(\mathrm{~s}^{-1}\right)$ the frequency of vibration of the solute species in an interstitial position, and $\alpha$ a parameter that depends on the type of interstitial site considered. In this theory the frequency $v$ is given by:

$$
v=\sqrt{\frac{E_{D}}{2 m \lambda^{2}}}
$$

where $\lambda(\mathrm{m})$ is the distance between two interstitial sites and $\mathrm{m}(\mathrm{kg})$ is the mass of the diffusing atom/molecule. However, equation (3) requires the knowledge of $\alpha$, which is known for tetrahedral and octahedral sites in bcc and $f c c$ structures [61], but not for the wurtzite lattice. The determination of $\alpha$ and $D_{0}$ is consequently necessary and is established in Appendix; the results are briefly given below.

The diffusion in the hexagonal lattice is anisotropic. Along the $\mathbf{c}$ direction, it is one dimensional while in the basal plane it is two dimensional and the possible directions for diffusion are $\mathbf{a}, \mathbf{b}_{\mathbf{1}}$ or 
$\mathbf{b}_{2}$ (Figure A1 b). The diffusion coefficient in each direction was obtained using Fick's laws. The results are, in the c direction:

$$
\mathrm{D}_{H_{2}}^{\mathrm{c}}(\mathrm{T})=v_{\mathrm{c}} \lambda_{\mathrm{c}}^{2} \exp \left(-\frac{\mathrm{E}_{\mathrm{D}}^{\mathrm{c}}}{\mathrm{k}_{\mathrm{B}} \mathrm{T}}\right)=\sqrt{\frac{\mathrm{E}_{\mathrm{D}}^{\mathrm{c}} \lambda_{\mathrm{c}}}{2 \mathrm{~m}}} \exp \left(-\frac{\mathrm{E}_{\mathrm{D}}^{\mathrm{c}}}{\mathrm{k}_{\mathrm{B}} \mathrm{T}}\right)
$$

And in the basal planes:

$$
\mathrm{D}_{\mathrm{H}_{2}}^{\|}(\mathrm{T})=\frac{3}{2} v_{\|} \lambda_{\|}^{2} \exp \left(-\frac{\mathrm{E}_{\mathrm{D}}^{\|}}{\mathrm{k}_{\mathrm{B}} \mathrm{T}}\right)=\frac{3}{2} \sqrt{\frac{\mathrm{E}_{\mathrm{D}}^{\|} \lambda_{\|}}{2 \mathrm{~m}}} \exp \left(-\frac{\mathrm{E}_{\mathrm{D}}^{\|}}{\mathrm{k}_{\mathrm{B}} \mathrm{T}}\right)
$$

The full demonstration can be found in Appendix.

\section{3. Comparison with experiment}

Using equations (10) and (11) one can finally derive the expression of the diffusion coefficient along direction $\mathrm{c}$ and in the basal plane of $\mathrm{BeO}$; they are $\mathrm{D}_{\mathrm{H}_{2}}^{\mathrm{c}}(\mathrm{T})=1.5 \times 10^{-6} \exp \left(-\frac{1.81 \mathrm{eV}}{\mathrm{k}_{\mathrm{B}} \mathrm{T}}\right) \mathrm{m}^{2} \mathrm{~s}^{-1}$ and $\mathrm{D}_{\mathrm{H}_{2}}^{\|}(\mathrm{T})=2.4 \times 10^{-6} \exp \left(-\frac{1.45 \mathrm{eV}}{\mathrm{k}_{\mathrm{B}} \cdot \mathrm{T}}\right) \mathrm{m}^{2} \mathrm{~s}^{-1}$, respectively.

Fowler et al. [35] derived the diffusion coefficient of hydrogen by measuring the release rate of tritium from single crystal $\mathrm{BeO}$ (between $920 \mathrm{~K}$ and $1470 \mathrm{~K}$ ) and from sintered $\mathrm{BeO}$ (between $770 \mathrm{~K}$ and $1220 \mathrm{~K})$; they found $\mathrm{D}_{\exp }^{1-\mathrm{SC}}(\mathrm{T})=1.1 \times 10^{-6} \exp \left(-\frac{2.3 \mathrm{eV}}{\mathrm{k}_{\mathrm{B}} \mathrm{T}}\right) \mathrm{m}^{2} \mathrm{~s}^{-1} \quad$ and $\mathrm{D}_{\text {exp }}^{1-\operatorname{sintered}}(\mathrm{T})=7.0 \times 10^{-6} \exp \left(-\frac{2.1 \mathrm{eV}}{\mathrm{k}_{\mathrm{B}} \mathrm{T}}\right) \mathrm{m}^{2} \mathrm{~s}^{-1}$. Macaulay-Newcombe et al. [34] derived a lower limit for the diffusion coefficient of hydrogen in BeO by fitting TDS spectra of deuterium desorbing from polycrystalline $\mathrm{BeO}$ exposed to deuterium gas between $770 \mathrm{~K}$ and $870 \mathrm{~K}: \mathrm{D}_{\exp }^{2}(\mathrm{~T}) \geq 7.0 \times 10^{-5} \exp \left(-\frac{2.1 \mathrm{eV}}{\mathrm{k}_{\mathrm{B}} \mathrm{T}}\right) \mathrm{m}^{2} \mathrm{~s}^{-1}$ 
The corresponding diffusion coefficients are plotted in Figure 9. As the data from MacaulayNewcombe et al. [34] were obtained with deuterium, they were rescaled with the square root of the mass ratio between deuterium and hydrogen. A similar rescaling is done for Fowler et al. data [35] since they have been obtained with tritium.

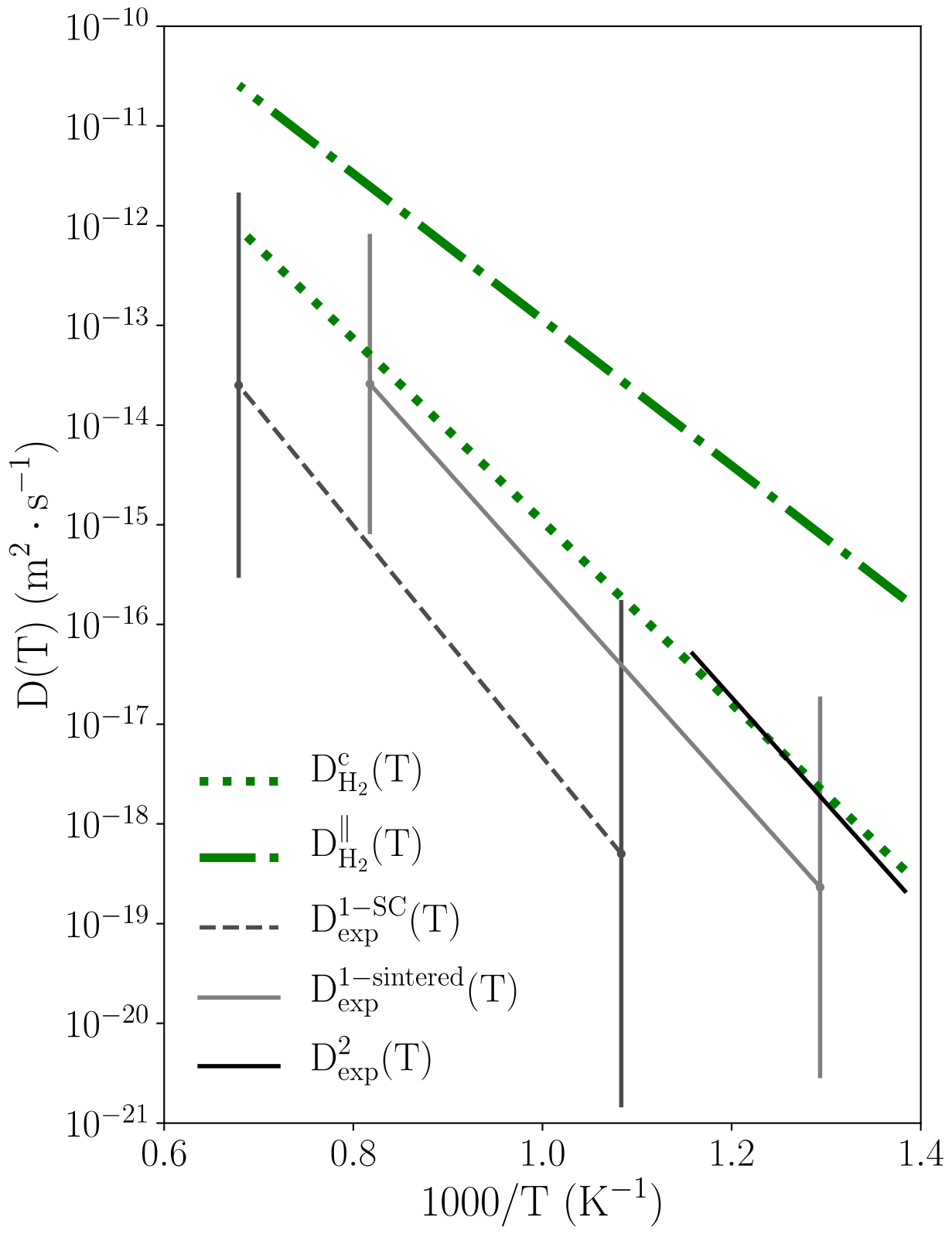

Figure 8. Comparison between the calculated diffusion coefficient of an $\mathrm{H}_{2}$ molecule in wurtzite $\mathrm{BeO}$ and the experimental data. $\mathrm{D}_{\mathrm{H}_{2}}^{\mathrm{c}}(\mathrm{T})$ : calculated diffusion coefficient along the direction $\mathbf{c}$. $\mathrm{D}_{\mathrm{H}_{2}}^{\|}(\mathrm{T})$ : calculated diffusion coefficient parallel to the hexagonal planes, $\mathrm{D}_{\exp }^{1-\mathrm{SC}}(\mathrm{T})$ : Fowler et al. 
[35] in single crystal $\mathrm{BeO}(920 \mathrm{~K}-1480 \mathrm{~K})$ including error bars. $\mathrm{D}_{\text {exp }}^{1-\text { sintered }}(\mathrm{T})$ : Fowler et al. [35] in sintered $\mathrm{BeO}(770 \mathrm{~K}-1220 \mathrm{~K})$ including error bars. $\mathrm{D}_{\exp }^{2}(\mathrm{~T})$ : Macaulay-Newcombe et al. [34] in polycrystalline $\mathrm{BeO}(720 \mathrm{~K}-870 \mathrm{~K})$ (lower limit).

The calculated diffusion coefficient $\mathrm{D}_{\mathrm{H}_{2}}^{\mathrm{c}}(\mathrm{T})$ agrees well with the experimental data; it is in close correspondence with the results from Fowler et al [35] and falls within the experimental error bars over the full range of temperature. The agreement with $\mathrm{D}_{\mathrm{H}_{2}}^{\|}(\mathrm{T})$ is weaker for $\mathrm{D}_{\mathrm{H}_{2}}^{\mathrm{c}}(\mathrm{T})$; it lies one or two orders of magnitude higher than the upper bond of the experimental error bars.

A strong anisotropy exists in the diffusion of $\mathrm{H}_{2}$ in $\mathrm{BeO}$. Consequently, one can expect that different crystal orientation would lead to different diffusion coefficients. An orientation like (0001) would lead to the diffusion in the $\mathbf{c}$ direction while an orientation like (ijk0) (at least one of the $\mathrm{i}, \mathrm{j}$ or $\mathrm{k} \neq 0$ ) would lead to the diffusion coefficient parallel to the basal plane. A theoretical study by Freeman et al. [62] suggests that the growth of $\mathrm{BeO}$ crystal is oriented in the $\mathbf{c}$ direction due to graphitic nanofilms as precursors. Taking this effect into account, the diffusion would preferentially occur along the c direction. This reinforces the agreement between the experimental data and the calculated data reported here.

\section{Conclusions}

In this work, we established the stable states of hydrogen within in perfect wurtzite beryllium oxide at finite temperature and pressure with an emphasis on conditions relevant to hydrogenimplanted materials. The most stable states for hydrogen are non-magnetic; they are $\mathrm{H}^{+}, \mathrm{H}^{-}$and the $\mathrm{H}_{2}$ molecule. It is also found that magnetic states are unstable in any conditions. At room 
temperature, hydrogen prefers the $\mathrm{H}^{+/}$states, but the overall concentration of hydrogen in beryllium oxide is negligible. In conditions relevant to hydrogen implantation, it is also found the $\mathrm{H}_{2}$ dominates at concentration as low as $10^{-40}$ at.fr. When an equilibrium with an hydrogen gas phase at standard pressure is considered, hydrogen in $\mathrm{BeO}$ mostly exists in its molecular $\mathrm{H}_{2}$ state at temperatures near and above $900 \mathrm{~K}$; this is the lower end of the temperature domain in experiments measuring the diffusion coefficient for hydrogen in $\mathrm{BeO}$. Based on these results, the diffusion coefficient was computed and is consistent with previous experimental measurements. This suggest that hydrogen in its molecular form must be considered in further models and experimental interpretation considering hydrogen diffusion and hydrogen-implanted beryllium oxide.

\section{Acknowledgments}

This work has been carried out within the framework of the EUROfusion Consortium and has received funding from the Euratom research and training programme 2014-2018 under grant agreement No 633053. The views and opinions expressed herein do not necessarily reflect those of the European Commission. The authors of this work were granted access to the HPC resources of IDRIS and CINES under the allocation A0020806612 made by GENCI (Grand Equipement National de Calcul Intensif) and to the Marconi Supercomputer at CINECA Super Computing Application and Innovation Department, Bologna, Italy.

\section{Appendix}

The diffusion in the hexagonal lattice is anisotropic: 
- along the c direction, it is one dimensional and each interstitial site of coordinate $(i)$ has two nearest neighbors at $(i \pm 1)$ (Figure A1).

- In the basal plane, it is two dimensional with coordinates $(i, j)$ in a hexagonal network (Figure $8 b$ ) and has six. The possible direction for diffusion are $\mathbf{a}, \mathbf{b}_{\mathbf{1}}$ or $\mathbf{b}_{\mathbf{2}}$ (Figure $6 \mathrm{~b}$ ). In Cartesian coordinates, they are: $\mathbf{a}=\mathbf{y}, \mathbf{b}_{\mathbf{1}}=\frac{\sqrt{3}}{2} \mathbf{x}+\frac{1}{2} \mathbf{y}$ and $\mathbf{b}_{\mathbf{2}}=\frac{\sqrt{3}}{2} \mathbf{x}-\frac{1}{2} \mathbf{y}$.

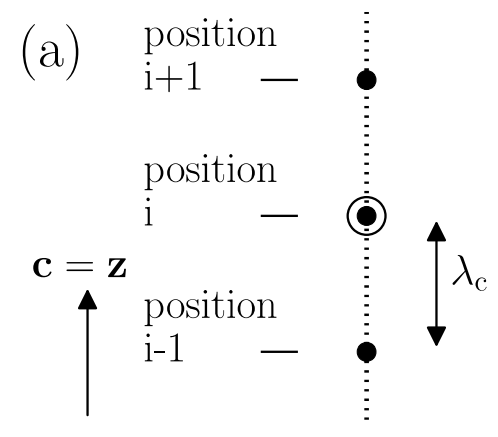

(b)

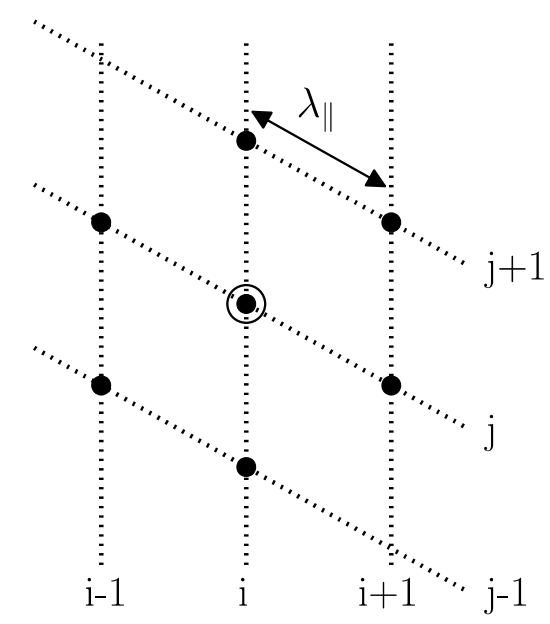

Figure A1. Nearest interstitial Oh positions for (a) diffusion along $\boldsymbol{c}$ direction and (b) diffusion parallel to the basal plane.

\section{A1. In the $\boldsymbol{c}$ direction}

Let's call $c_{\mathrm{i}}$ the concentration of the diffusing species at position (i). A particle at $(i \pm 1)$ has $\frac{1}{2}$ chance to increase the population at $(i)$ - Figure A1. Thus, the growth rate of $c_{i}$ is:

$$
\mathrm{dc}_{\mathrm{i}}=\left(\frac{1}{2} c_{\mathrm{i}-1}-\mathrm{c}_{\mathrm{i}}+\frac{1}{2} c_{\mathrm{i}+1}\right) \mathrm{p}_{\mathrm{c}} v_{\mathrm{c}} \exp \left(-\frac{E_{D}^{c}}{\mathrm{k}_{\mathrm{B}} \mathrm{T}}\right) \mathrm{dt}
$$


where $v_{c}$ is the frequency given by equation (4), $\mathrm{p}_{\mathrm{c}}=2$ is the probability factor (or the number of equivalent paths to reach another interstitial site) [22], $\mathrm{E}_{\mathrm{D}}^{\mathrm{c}}$ is the calculated energy barrier for diffusion in the c direction. In equation (A1), the term between brackets can be understood as the discretization of the second derivative along the $\mathbf{c}$ direction or $\mathbf{z}$ in Cartesian space: $\frac{\partial^{2} c_{i}}{\partial z^{2}}=$ $\frac{c_{i-1}-2 c_{i}+c_{i+1}}{d z^{2}}$. Since the smallest distance between two interstitial sites is $\lambda_{c}$, one assumes $d z=\lambda_{c}$ and obtains, $\frac{\mathrm{dc}_{\mathrm{i}}}{\mathrm{dt}}=v_{\mathrm{c}} \lambda_{\mathrm{c}}^{2} \exp \left(-\frac{\mathrm{E}_{\mathrm{D}}^{\mathrm{c}}}{\mathrm{k}_{\mathrm{B}} \mathrm{T}}\right) \frac{\partial^{2} \mathrm{c}}{\partial \mathrm{z}^{2}}$. According to Fick's laws on diffusion, the diffusion coefficient in the c direction:

$$
D_{H_{2}}^{c}=v_{c} \lambda_{c}^{2} \exp \left(-\frac{E_{D}^{c}}{k_{B} T}\right)=\sqrt{\frac{E_{D}^{c} \lambda_{c}}{2 m}} \exp \left(-\frac{E_{D}^{c}}{k_{B} T}\right)
$$

It can be pointed out here that $D_{0}=\frac{n}{2 d} v_{c} \lambda_{c}^{2}$ where the number of nearest interstitial neighbor is $\mathrm{n}=2$ and the dimensionality of the motion is $\mathrm{d}=1$.

\section{A2. In the basal planes}

The concentration of a diffusing particle at the position $(i, j)$ is $c_{i, j}$. Since there are 6 nearest interstitial neighbors (Figure $8 b$ ), there are $\frac{1}{6}$ chance to increase the concentration $c_{i, j}$ from particles in a neighboring site of $(i, j)$. Thus the growth rate of $c_{i, j}$ is:

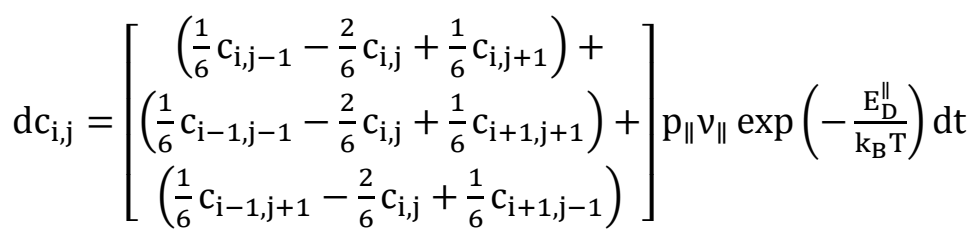

$\mathrm{p}_{\|}=6$. Is the probability factor or the number of path to reach another interstitial site [22]. Equation (A3) gives the evolution over the time of $f c_{i, j}$ and corresponds to the second derivative 
along the vectors $\mathbf{a}, \mathbf{b}_{1}$ and $\mathbf{b}_{2}: \frac{\mathrm{dc}_{\mathrm{i}, \mathrm{j}}}{\mathrm{dt}}=v_{\|} \exp \left(-\frac{\mathrm{E}_{\mathrm{D}}^{\|}}{\mathrm{k}_{\mathrm{B}} \mathrm{T}}\right)\left[\frac{\partial^{2} \mathrm{c}}{\partial \mathrm{a}^{2}}{ }_{\mathrm{i}, \mathrm{j}}+\frac{\partial^{2} \mathrm{c}}{\partial \mathrm{b}_{1, \mathrm{j}}^{2}}+\frac{\partial^{2} \mathrm{c}}{\partial \mathrm{b}_{2 \mathrm{i}, \mathrm{j}}^{2}}\right] \lambda_{\|}^{2}$. In Cartesian coordinates, $\quad$ it $\quad$ is: $\quad \frac{\partial^{2} \mathrm{c}}{\partial \mathrm{a}^{2}}+\frac{\partial^{2} \mathrm{c}}{\partial \mathrm{b}_{1}^{2}}+\frac{\partial^{2} \mathrm{c}}{\partial \mathrm{b}_{2}^{2}}=\frac{3}{2}\left(\frac{\partial^{2} \mathrm{c}}{\partial \mathrm{x}^{2}}+\frac{\partial^{2} \mathrm{c}}{\partial \mathrm{y}^{2}}\right) \quad$ which $\quad$ leads to: $\frac{\mathrm{dc}_{\mathrm{i}, \mathrm{j}}}{\mathrm{dt}}=\frac{3}{2} v_{\|} \lambda_{\|}^{2} \exp \left(-\frac{\mathrm{E}_{\mathrm{D}}^{\|}}{\mathrm{k}_{\mathrm{B}} \mathrm{T}}\right)\left[\frac{\partial^{2} \mathrm{c}}{\partial \mathrm{x}^{2}}{ }_{\mathrm{i}, \mathrm{j}}+\frac{\partial^{2} \mathrm{c}}{\partial \mathrm{y}_{1, \mathrm{j}}^{2}}\right]$. The Fick's laws on diffusion leads to the expression of the diffusion coefficient parallel to basal planes:

$$
D_{H_{2}}^{\|}=\frac{3}{2} v_{\|} \lambda_{\|}^{2} \exp \left(-\frac{E_{D}^{\|}}{k_{B} T}\right)=\frac{3}{2} \sqrt{\frac{E_{D}^{\|} \lambda_{\|}}{2 m}} \exp \left(-\frac{E_{D}^{\|}}{k_{B} T}\right)
$$

It can be pointed out that $D_{0}=\frac{n}{2 d} v_{\|} \lambda_{\|}^{2}$, in which the number of nearest neighbor is $\mathrm{n}=6$ and the dimensionality of the motion is $\mathrm{d}=2$.

\section{References}

[1] V. Philipps, P. Mertens, G. F. Matthews, H. Maier and JET-EFDA contributors, "Overview of the JET ITER-like Wall Project," Fusion Eng. Des. 85, p. 1581-1586, 2010.

[2] S. Brezinsek and JET-EFDA contributors, "Plasma-surface interaction in Be/W environment: Conclusions drawn from the JET-ILW for ITER," J. Nucl. Mater. 463, pp. 11-21, 2015.

[3] A. Loarte, B. Lipschultz, A. S. Kukushkin, G. F. Mathews, P. C. Stangeby and al., "Chapter 4: Power and particle control," Nucl. Fusion 47 S203, 2007.

[4] S. Brezinsek, J. W. Coenen, T. Schwarz-Selinger and al, "Plasma-wall interaction studies within the EUROfusion consortium: progress on plasma-facing components development and qualification," Nucl. Fusion 57, p. 116041, 2017.

[5] M. Shimada, R. A. Pitts, S. Ciattaglia, S. Carpentier, C. H. Choi, G. Dell Orco, T. Hirai, A. Kukushkin, S. 
Lisgo, J. Palmer, W. Shu and E. Veshchev, "In-vessel dust and tritium control strategy in ITER," J. Nucl. Mater. 438, pp. S996-S1000, 2013.

[6] K. Schmid, U. von Toussaint and T. Schwarz-Selinger, "Transport of hydrogen in metals with occupancy dependent trap energies," J. Appl. Phys. 116, p. 134901, 2014.

[7] E. A. Hodille, X. Bonnin, R. Bisson, T. Angot, C. S. Becquart, J.-M. Layet and C. Grisolia, "Macroscopic rate equation modeling of trapping/detrapping of hydrogen isotopes in tungsten materials," J. Nucl. Mater. 467, pp. 424-431, 2015.

[8] M. J. Baldwin, T. Schwarz-Selinger and R. P. Doerner, "Experimental study and modelling of deuterium thermal release from Be-D co-deposited layers," Nucl. Fusion 54, p. 073005, 2014.

[9] M. J. Baldwin, T. Schwarz-Selinger, J. H. Yu and R. P. Doerner, "TMAP-7 simulation of D2 thermal release data from Be co-deposited layers," J. Nucl. Mater. 438, pp. S976-S970, 2013.

[10] M. Oberkofler, M. Reinelt and C. Linsmeier, "Retention and release mechanisms of deuterium implanted into beryllium," Nucl. Instr. Meth. Phys. Res. B 269, pp. 1266-1270, 2011.

[11] R. Piechoczek, M. Reinelt, M. Oberkofler, A. Allouche and C. Linsmeier, "Deuterium trapping and release in Be(0001), Be(11-20) and polycrystalline beryllium," J. Nucl. Mater. 438, pp. S2072-S1075, 2013.

[12] M. Reinelt, A. Allouche, M. Oberkofler and C. Linsmeier, "Retention mechanisms and binding states of deuterium implanted into beryllium," New Journal of Physics 11, p. 043023, 2009.

[13] G. De Temmerman, M. J. Baldwin, D. Anthoine, K. Heinola, A. Jan, I. Jepu, J. Likonen, C. P. Lungu, C. Porosnicu and R. A. Pitts, "Efficiency of thermal outgassing for tritium retention measurement and removal in ITER," Nucl. Mater. Energy 12, pp. 267-272, 2017.

[14] T. Oda, D. Zhu and Y. Watanabe, "Kinetic Monte Carlo simulation on influence of vacancy on 
hydrogen diffusivity in tungsten," J. Nucl. Mater. 467, pp. 439-447, 2015.

[15] U. von Toussaint, T. Schwarz-Selinger and K. Schmid, "First-passage kinetic Monte Carlo on lattices: Hydrogen transport in lattices with traps," J. Nucl. Mater. 463, pp. 1075-1079, 2015.

[16] E. Safi, G. Valles, A. Lasa and K. Nordlund, "Multi-Scale modelling to relate beryllium surface temperature, deuterium concentration and erosion in fusion reactor environment," J. Phys. D: Appl. Phys. 50, p. 204003, 2017.

[17] E. Safi, C. Björkas, A. Lasa, K. Nordlund, I. Sukuba and M. Probst, "Atomistic simulations of the effect of reactor-relevant parameters on Be sputtering," J. Nucl. Mater. 463, pp. 805-809, 2015.

[18] C. Björkas, D. Borodin, A. Kirschner, R. K. Janev, D. Nishijima, R. Doerner and K. Nordlund, "Molecules can be sputtered also from pure metals: sputtering of beryllium hydride by fusion plasma-wall interactions," Plasma Phys. Control. Fusion 55, p. 074004, 2013.

[19] J. Byggmästar, E. A. Hodille, Y. Ferro and K. Nordlund, "Analytical bond order potential for simulations of $\mathrm{BeO} 1 \mathrm{D}$ and 2D nanostructures and plasma-surface interactions," J. Phys.: Condens. Matter 30, p. 135001, 2018.

[20] A. Allouche and Y. Ferro, "First-principles study of hydrogen retention and diffusion in beryllium oxide," Solid State lonics 272, pp. 91-100, 2015.

[21] A. G. Marinopooulos, R. C. Vilao, R. B. L. Vieira, H. V. Alberto, J. M. Gil, M. V. Yakushev, R. Scheuermann and T. Goko, "Defect levels and hyperfine constants of hydrogen in beryllium oxide from hybrid-functional calculations and muonium spectroscopy," Phil. Mag., vol. 97, no. 24, pp. 2108-2128, 2017.

[22] N. Fernandez, Y. Ferro and D. Kato, "Hydrogen diffusion and vacancies formation in tungsten: Density Functional Theory calculations and statistical models," Acta Mater. 94, pp. 307-318, 2015. 
[23] K. Heinola and T. Ahlgren, "First-principles study of H on the reconstructed W(100) surface," Phys. Rev. B 81, p. 073409, 2010.

[24] K. Heinola, T. Ahlgren, K. Nordlund and J. Keinonen, "Hydrogen interaction with point defects in tungsten," Phys. Rev. B 82, p. 094102, 2010.

[25] Z. A. Piazza, M. Ajmalghan, Y. Ferro and R. D. Kolasinski, "Saturation of tungsten surfaces with hydrigen: A density functional theory study complemented by low energy ion scattering and direct recoil spectroscopy data," Acta Mater. 145, pp. 388-398, 2018.

[26] S. C. Middleburgh and R. W. Grimes, "Defects and transport processes in beryllium," Acta Mater. 59, pp. 7095-7103, 2011.

[27] P. Zhang, J. Zhao and B. Wen, "Retention and diffusion of $\mathrm{H}, \mathrm{He}, \mathrm{O}, \mathrm{C}$ impurities in Be," J. Nucl. Mater. 423, pp. 164-169, 2012.

[28] L. Ferry, F. Virot, M. Barrachin, Y. Ferro, C. Pardanaud, D. Matveev, M. Wensing, T. Dittmar, M. Koppen and C. Linsmeier, "Theoretical investigation on the point defect formation energies in beryllium and comparison with experiments," Nucl. Mater. Energy 12, pp. 453-457, 2017.

[29] H. Li and J. Robertson, "Behavior of hydrogen in wide band gap oxides," J. Appl. Phys. 115, p. 203708, 2014.

[30] C. G. Van de Walle and J. Neugebauer, "Universal alignment of hydrogen levels in semiconductors, insulators and solutions," Nature, vol. 423, p. 626, 2003.

[31] C. G. Van de Walle, "Hydrogen as a Cause of Doping in Zinc Oxide," Phys. Rev. Lett., vol. 85, no. 5, p. $1012,2000$.

[32] A. F. Wright, "Influence of crystal structure on the lattice sites and formation energies of hydrogen in wurtzite and zinc-blende GaN," Phys. Rev. B, vol. 60, no. 8, pp. R5101-R5104, 1999. 
[33] S. Limpijumnong and C. G. Van de Walle, "Stability, diffusivity, and vibrational properties of monatomic and molecular hydrogen in wurtzite GaN," Phys. Rev. B 68, p. 235203, 2003.

[34] R. G. Macaulay-Newcombe and D. A. Thompson, "The effects of surface contamination on absorption and desorption of deuterium in beryllium and beryllium oxide," J. Nucl. Mater. 212-215, pp. 942-947, 1994.

[35] J. D. Fowler, D. Chandra, T. S. Elleman, A. W. Payne and K. Verghese, "Tritium diffusion in Al2O3 and BeO," J. Amer. Ceram. Soc., vol. 60, no. 3-4, p. 155, 1977.

[36] C. Pardanaud, M. Rusu, C. Martin, G. Giacometti, P. Roubin, Y. Ferro, A. Allouche, M. Oberkofler, M. Köppen, T. Dittmar and C. Linsmeier, "Hydrogen retention in beryllium: concentration effect and nanocrystalline growth," J. Phys. Condens. Matter 27, p. 475401, 2015.

[37] M. I. Rusu, C. Pardanaud, Y. Ferro, G. Giacometti, C. Martin, Y. Abbad, P. Roubin, M. Minissale, L. Ferry, F. Virot, M. Barrachin, C. P. Lungu, C. Porosnicu, P. Dinca, M. Lungu, M. Köppen, P. Hansen and C. Linsmeier, "Preparing the future post-mortem analysis of beryllium-based JET and ITER samples by multi-wavelengths Raman spectroscopy on implanted Be, and co-deposited Be," Nucl. Fusion 57, p. 076035, 2017.

[38] P. Giannozzi, S. Baroni, N. Bonini, M. Calandra, R. Car, C. Cavazzoni, D. Ceresoli, G. L. Chiarotti, M. Cococcioni, I. Dabo, A. Dal Corso, S. de Gironcoli, S. Fabris, G. Fratesi, R. Gebauer, U. Gerstmann, C. Gougoussis, A. Kokalj, M. Lazzeri, L. Martin-Samos, N. Marzari, F. Mauri, R. Mazzarello, S. Paolini, A. Pasquarello, L. Paulatto, C. Sbraccia, S. Scandolo, G. Sclauzero, A. P. Seitsonen, A. Smogunov, P. Umari and R. M. Wentzcovitch, "QUANTUM ESPRESSO: a modular and open-source software project for quantum simulations of materials," J. Phys.: Condens Matter 21, p. 395502, 2009.

[39] J. P. Perdew, K. Burke and M. Ernzerhof, "Generalized Gradient Approximation made simple," Phys. 
Rev. Lett., vol. 77, no. 18, p. 3865, 1996.

[40] D. Vanderbilt, "Soft self-consistent pseudopotentials in a generalized eigenvalue formalism," Phys. Rev. $B$, vol. 41 , no. 11 , p. 7892, 1990.

[41] R. M. Hazen and L. W. Finger, "High-pressure and high temperature crystal chemistry of beryllium oxide," J. Appl. Phys. 59, p. 3728, 0986.

[42] P. Haas, F. Tran and P. Blaha, "Calculation of the lattice constant of solids with semilocal functionals," Phys. Rev. B 79, p. 085104, 2009.

[43] G. Vidal-Valat, J.-P. Vidal, K. Kurki-Suonio and R. Kurki-Suonio, "Multipole Analysis of X-ray Diffraction Data on BeO," Acta Cryst. A43, pp. 540-550, 1987.

[44] D. M. Roessler and W. C. Walker, "Electronic spectrum of crystalline beryllium oxide," J. Phys. Chem. Solids, vol. 30, pp. 157-167, 1969.

[45] A. J. Cohen, P. Mor-Sanchez and W. Yang, "Insights into Current Limitations of Density Functional Theory," Science, vol. 321, pp. 792-794, 2008.

[46] C. Freysoldt, B. Grabowski, T. Hickel and J. Neugebauer, "First-principles calculations for point defects in solids," Rev. Mod. Phys., vol. 86, p. 253, 2014.

[47] C. Freysoldt, J. Neugebauer and C. G. Van de Walle, "Fully Ab initio Finite-Size Corrections for Charged-Defect Supercell Calculations," Phys. Rev. Lett. 102, p. 016402, 2009.

[48] "SXDEFECTALIGN," [Online]. Available: https://sxrepo.mpie.de/projects/sphinx-add-ons/files.

[49] G. Makov and M. C. Payne, "Periodic boundary conditions in ab initio calculations," Phys. Rev. B, vol. 51, no. 7, p. 4014, 1995.

[50] M. A. Subramanian, R. D. Shannon, B. H. T. Chai, M. M. Abraham and M. C. Wintersgill, "Dielectric Constants of $\mathrm{BeO}, \mathrm{MgO}$ and $\mathrm{CaO}$ Using the Two-Terminal Method," Phys. Chem. Minerals 16, pp. 
741-746, 1989.

[51] S. Baroni, S. de Gironcoli, A. Dal Corso and P. Giannozzi, "Phonons and related crystal properties from density-functional perturbation theory," Rev. Mod. Phys. 73, pp. 515-562, 2001.

[52] G. Gouadec and P. Colomban, "Raman spectroscopy of nanomaterials: How spectra relate to disorder, particle size and mechanical properties," Prog. Cryst. Growth Char. Mater. 53, pp. 1-56, 2007.

[53] E. Weinan, R. Weiqing and E. Vanden-Eijnden, "String method for the study of rare events," Phys. Rev. B 66, p. 052301, 2002.

[54] Y. Kanai, A. Tilocca and A. Selloni, "First-principles string molecular dynamics: An efficient approach for finding chemical reaction pathways," J. Chem. Phys., vol. 121, no. 8, p. 3359, 2004.

[55] L. E. Sutton, Tables of Inter-Atomic Distances, London: Chemical Society: Chemical Society Special Publication, 1958.

[56] J. Neugebauer and C. Van de Walle, "Hydrogen in GaN: novel aspects of a common impurity," Phys. Rev. Lett., vol. 75, no. 24, pp. 4452-4455, 1995.

[57] S. M. Myers, A. F. Wright, G. A. Petersen, C. H. Seager, W. R. Wampler, M. H. Crawford and J. Han, "Equilibrium state of hydrogen in gallium nitride: Theory and experiment," J. Appl. Phys., vol. 88, no. 8, pp. 4676-4687, 2000.

[58] N. W. Ashcroft and N. D. Mermin, Solid State Physics, Saunders College Publishing, 1976.

[59] R. Kircheim, "Solid Solution of Hydrogen in Complex Materials," Solid State Physics 59, pp. 203-291, 2004.

[60] S. M. Myers and A. F. Wright, "Theoretical description of $\mathrm{H}$ behavior in GaN p-n juntions," J. Appl. Phys. , vol. 90, no. 11, pp. 5612-5622, 2001. 
[61] C. Wert and C. Zener, "Interstitial Atomic Diffusion Coefficients," Phys. Rev., vol. 76, no. 8, p. 1169, 1949.

[62] C. L. Freeman, F. Claeyssens and N. L. Allan, "Graphitic nanofilm as precursors to wurtzite films: Theory," Phys. rev. Lett. 96, p. 066102, 2006. 